\title{
Menstrual migraine: a clinical review
}

\section{E Anne MacGregor}

\section{Overview}

Migraine attacks are often associated with menstruation in many, but not all, women with migraine. To date, no hormonal abnormalities have been identified in these women and it appears that normal hormonal fluctuations are associated with an abnormal central nervous system response. Diagnosis of migraine and confirmation of menstrual association is clinical, based on headache history and review of diary cards. Tests of hormone levels are rarely useful. Standard drugs to treat the acute symptoms suffice for the majority of women with monthly attacks. If acute therapy alone is inadequate, pre-emptive treatment of the expected menstrual headache with perimenstrual estradiol, triptans or non-steroidal anti-inflammatory drugs (NSAIDs) may be effective. Suppression of the menstrual cycle with anovulatory contraceptive agents is an additional option, particularly for women who also require contraception. A variety of other treatments have been studied, but the quality of evidence for their use is generally poor.

\section{Search strategy}

Data for this review were identified by a MEDLINE search using the following search terms: estrogen, estradiol, menstruation, menstrual cycle, menstrual migraine, menstrually related migraine, menstrually associated migraine, migraine and progesterone. The resultant search identified 554 publications. The Cochrane search strategy for identifying reports of randomised controlled trials was run on this database. ${ }^{1}$ The search strategy identified 103 publications, which were scrutinised for relevancy to this review.

In addition, references from the author's own files, a hand search of the journals Cephalalgia and Headache, and peer-reviewed presentations at international congresses were considered.

\section{How common is migraine?}

The two most frequently encountered types of migraine differ only in their presence or absence of 'aura' (Box 1). ${ }^{2}$ About $70-80 \%$ of migraineurs experience attacks of migraine without aura (formerly known as common or simple migraine), $10 \%$ have migraine with aura (formerly known as classical or focal migraine) and 15-20\% have both types of attacks. Less than $1 \%$ of attacks are of aura alone, with no ensuing headache.

Migraine is equally common in both sexes before puberty, with increased female prevalence following menarche. ${ }^{3}$ At puberty, the incidence of migraine without aura rises in females, ${ }^{4}$ with $10 \%$ to $20 \%$ of women reporting migraine with menarche..$^{5}$ This sex difference becomes greater with increasing age, peaking during the early $40 \mathrm{~s}$ and declining thereafter. The lifetime prevalence of migraine is around $25 \%$ in women compared to only $8 \%$ in men. ${ }^{6-8}$

J Fam Plann Reprod Health Care 2007; 33(1): 36-47

(Accepted 12 November 2006)

The City of London Migraine Clinic, London, UK and Barts Sexual Health, St Bartholomew's Hospital, London, UK E Anne MacGregor, MFFP, Director of Clinical Research

Correspondence to: Dr Anne MacGregor, The City of London Migraine Clinic, 22 Charterhouse Square, London EC1M 6DX, UK. E-mail: anne.macgregor@sinoragram.co.uk
Box 1 International Headache Society classification of migraine without aura and migraine with aura ${ }^{2}$

\subsection{Migraine without aura}

Recurrent headache disorder manifesting in attacks lasting 4-72 hours. Typical characteristics of the headache are unilateral location, pulsating quality, moderate or severe intensity, aggravation by routine physical activity and association with nausea and/or photophobia and phonophobia.

Diagnostic criteria:

A. At least five attacks ${ }^{1}$ fulfilling criteria B-D

B. Headache attacks lasting 4-72 hours (untreated or unsuccessfully treated)

C. Headache has at least two of the following characteristics: 1. Unilateral location

2. Pulsating quality

3. Moderate or severe pain intensity

4. Aggravation by or causing avoidance of routine physical activity (e.g. walking or climbing stairs)

D. During headache at least one of the following

1. Nausea and/or vomiting

2. Photophobia and phonophobia

E. Not attributed to another disorder in the Appendix because of uncertainty over whether they should be regarded as separate entities

\subsubsection{Typical aura with migraine headache}

Typical aura consisting of visual and/or sensory and/or speech symptoms. Gradual development, duration no longer than 1 hour, a mix of positive and negative features and complete reversibility characterise the aura, which is associated with a headache

fulfilling criteria for '1.1 Migraine without aura'.

Diagnostic criteria:

A. At least two attacks fulfilling criteria B-D

B. Aura consisting of at least one of the following, but no motor weakness:

1. Fully reversible visual symptoms including positive features (e.g. flickering lights, spots or lines) and/or negative features (i.e. loss of vision)

2. Fully reversible sensory symptoms including positive features (i.e. pins and needles) and/or negative features (i.e. numbness)

3. Fully reversible dysphasic speech disturbance

C. At least two of the following:

1. Homonymous visual symptoms ${ }^{1}$ and/or unilateral sensory symptoms

2. At least one aura symptom develops gradually over $\geq 5$ minutes and/or different aura symptoms occur in succession over $\geq 5$ minutes

3. Each symptom lasts $\geq 5$ and $<60$ minutes

D. Headache fulfilling criteria B-D for ' 1.1 Migraine without aura' begins during the aura or follows aura within 60 minutes

E. Not attributed to another disorder

\section{Who gets menstrual migraine?}

More than $50 \%$ of women with migraine, both in the general population and presenting to specialist clinics, report an association between migraine and menstruation. ${ }^{9-14}$

For most women with menstrual attacks, migraine also occurs at other times of the month ('menstrually related' migraine) ${ }^{2,13}$ Fewer than $10 \%$ of women report migraine exclusively with menstruation and at no other time of the month ('true' or 'pure' menstrual migraine). ${ }^{2,11-14}$

\section{Prognosis}

Migraine is a fluctuating condition. A longitudinal study of 73 migraineurs over 40 years showed that attack frequency was variable with time, sometimes with long episodes of remission. ${ }^{15}$ Similarly, the association with menstruation is inconsistent with time. Although a few women report a constant association between migraine and menstruation since menarche, the majority report a gradual association between migraine and menstruation developing from their late 30 s, with 
Box 2 International Headache Society classification of pure menstrual migraine and menstrually related migraine ${ }^{2}$

A1.1.1 Pure menstrual migraine without aura

Diagnostic criteria:

A. Attacks, in a menstruating woman, fulfilling criteria for "1.1 Migraine without aura'

B. Attacks occur exclusively on Day $1 \pm 2$ (i.e. Days +2 to -3$)^{1}$ of menstruation ${ }^{2}$ in at least two out of three menstrual cycles and at no other times of the cycle

Notes:

1. The first day of menstruation is Day 1 and the preceding day is Day -1 ; there is no Day 0 .

2. For the purposes of this classification, menstruation is considered to be endometrial bleeding resulting from either the normal menstrual cycle or from the withdrawal of exogenous progestogens, as in the case of combined oral contraceptives and cyclical hormone replacement therapy.

A1.1.2 Menstrually-related migraine without aura

Diagnostic criteria:

A. Attacks, in a menstruating woman, fulfilling criteria for " 1.1 Migraine without aura'

B. Attacks occur on Day $1 \pm 2$ (i.e. Days -2 to +3 ) of menstruation in at least two out of three menstrual cycles and additionally at other times of the cycle

Notes:

1. The first day of menstruation is Day 1 and the preceding day is Day -1 ; there is no Day 0.

2. For the purposes of this classification, menstruation is considered to be endometrial bleeding resulting from either the normal menstrual cycle or from the withdrawal of exogenous progestogens, as in the case of combined oral contraceptives and cyclical hormone replacement therapy.

increasing prevalence in the years leading to menopause. Following the menopause, migraine prevalence declines. ${ }^{16}$ However, the female preponderance still persists after menopause with a female:male ratio of 2:1 after 70 years of age.

\section{Clinical characteristics \\ Definition}

The International Headache Society Classification of Headache Disorders (ICHD) includes specific definitions for pure menstrual migraine and menstrually related migraine (Box 2). ${ }^{2}$

Although some women report a link between their migraine attacks and ovulation, this has not been confirmed in epidemiological studies. ${ }^{13,17,18} \mathrm{~A}$ prospective study confirmed that the observed number of attacks associated with ovulation was not significantly different from the expected number of attacks. ${ }^{19}$

\section{When do migraines occur?}

The definitions for pure menstrual and menstrually related migraine were developed from numerous studies, all of which have shown that migraine is most likely to occur on or between 2 days before menstruation and the first 3 days of bleeding. ${ }^{13,18-26}$

In the largest study to date of migraine and the natural menstrual cycle, 693 cycles from 155 women were reviewed. ${ }^{18}$ In the 5 days leading up to menstruation, women were $25 \%$ more likely to have a migraine attack [relative risk (RR) 1.25]. This increased to $71 \%$ in the 2 days before menstruation (RR 1.71). The chance of migraine was more than two-fold on the first day of menstruation and during the 5 days afterward (RR 2.19). The risk was highest on the first day of menstruation and the following 2 days (RR 2.50).

\section{What is different about menstrual attacks?}

Menstrual attacks are almost invariably without aura, even in women who have attacks with aura at other times of the cycle. ${ }^{13,22,26,27}$
Of specific relevance to clinical practice is that attacks occurring at the time of menstruation are more severe and disabling, last longer and are less responsive to symptomatic medication. ${ }^{10,14,18,28-31}$ Within-woman analyses show that compared to migraine at other times of the cycle, migraine in the 2 days before menstruation was 2.1 times more likely to be severe; those occurring on the first 3 days of bleeding were 3.4 times more likely to be severe and almost 5 times more likely to be accompanied by vomiting. ${ }^{18}$ In women with menstrually related migraine referred to tertiary care centres, premenstrual (Days -2 and -1 ), menstrual (Days +1 and +2 ), and late menstrual (Days +3 to +7 ) attacks lasted longer than attacks at other times of the cycle. ${ }^{32}$ Premenstrual and menstrual attacks were also less responsive to acute treatment than attacks at other times of the cycle.

The resulting disability is important. Recent research by the World Health Organization has established migraine as a leading cause of years of life lived with a disabling condition: ranked twelfth for women compared to nineteenth for men. ${ }^{33}$ Of 389 people with migraine, $85 \%$ reported substantial reductions in their ability to do household work and chores, $45 \%$ missed family social and leisure activities, and $32 \%$ avoided making plans for fear of cancellation due to headaches. ${ }^{34}$ Work-related disability is more often reported for premenstrual migraines than for non-menstrual attacks $(p=0.006) .^{32}$ Similarly, time spent at less than $50 \%$ productivity is greater for menstrual than non-menstrual attacks $(p=0.01) .{ }^{35}$

Disability does not only affect the individual but extends to the family and work environment. In one study, living with or being related to a migraineur decreased nonmigraineurs' ability to participate in home/family life (moderate/great impact, 49\%) and social/leisure activities (moderate/great impact, $47 \%$ ). ${ }^{14}$

\section{Pathophysiology}

Estrogen (oestrogen) and progesterone are the main hormones that have been investigated in relation to migraine. Studies comparing levels of these hormones in women with menstrual migraine versus controls have not found any convincing differences. Research has focused on 'withdrawal' of estrogen and progesterone/progestogens as occurs during the luteal phase of the menstrual cycle and during the hormone-free interval of combined hormonal contraception. ${ }^{36-39}$ Since women with migraine using combined hormonal contraceptives still experience migraine during the hormone-free interval, it would seem that ovulation is not a prerequisite for menstrual attacks.

\section{Estrogen 'withdrawal'}

Somerville undertook several studies in a small group of women who had a history of pure menstrual migraine. He noted that a period of estrogen 'priming' with several days of exposure to high estrogen levels is necessary for migraine to result from estrogen 'withdrawal', as occurs in the late luteal phase of the menstrual cycle. ${ }^{40-42}$ This would explain why migraine is not associated with the transient estrogen surge at ovulation.

Several other studies support Somerville's estrogen withdrawal theory. Epstein et al. noted that the extent of decline from peak to trough estrogen was greater in all 14 women with migraine in their study compared to eight women in the control group who did not have migraine..$^{43}$ They concluded that variation in hormonal activity might be a potentially relevant factor in all women with migraine; factors additional to the hormonal environment could account for the development of 'menstrual' attacks. Lichten et al. studied 28 postmenopausal women challenged with 


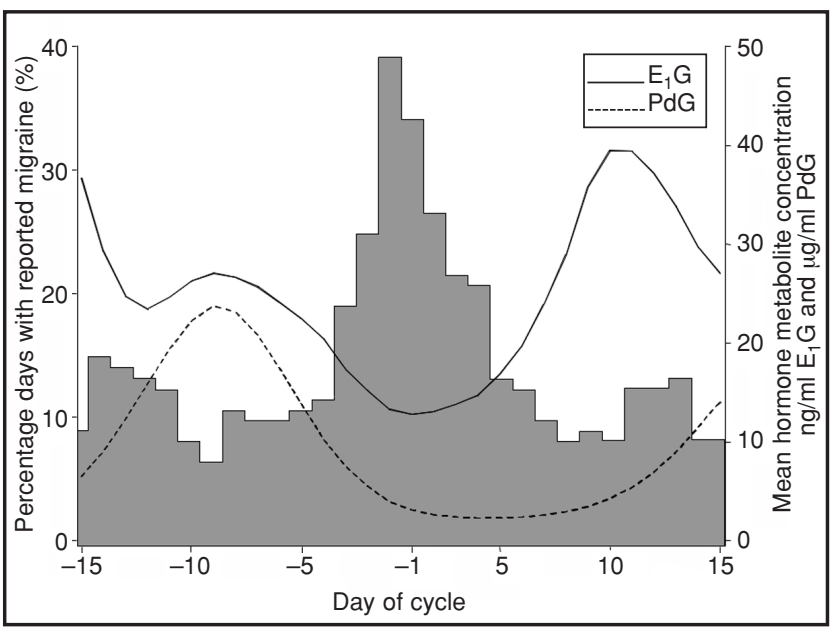

Figure 1 Incidence of migraine, urinary estrone-3-glucuronide $\left(E_{1} G\right)$ and pregnanediol-3-glucuronide (PdG) levels on each day of the menstrual cycle in 120 cycles from 38 women. Figure reproduced with permission from MacGregor et al. ${ }^{19}$

estrogen, confirming that in women with a history of premenopausal menstrually related migraine a drop in serum estrogen could precipitate migraine and that a period of estrogen priming was a necessary prerequisite. 39

MacGregor et al. studied 38 women with pure menstrual or menstrually related migraine aged 29-49 (mean, 43) years. Urine was collected daily for assay over three menstrual cycles and analysed for luteinising hormone $(\mathrm{LH}), \quad$ estrone-3-glucuronide $\left(\mathrm{E}_{1} \mathrm{G}\right)$, pregnanediol-3-glucuronide $(\mathrm{PdG})$ and follicle-stimulating hormone (FSH). ${ }^{19}$ Migraine was inversely associated with urinary estrogen levels across the menstrual cycle (Figure 1). Attacks were significantly more likely to occur in association with falling estrogen in the late luteal/early follicular phase of the menstrual cycle and significantly less likely to occur during the subsequent part of the follicular phase during which estrogen levels rose.

If the estrogen 'withdrawal' theory is correct, stabilising estrogen fluctuations by maintaining high, stable levels should prevent migraine. In support of this, Somerville showed that migraine could be postponed by maintaining high plasma estradiol levels with an intramuscular injection of long-acting estradiol valerate in oil; migraine subsequently occurred when the plasma estradiol fell. ${ }^{40}$ This finding also supports the lack of effect of progesterone on migraine, since if progesterone was an important factor then the timing of menstrual attacks would have been unaffected by the use of estrogen supplements. Somerville further attempted to control estrogen fluctuations with oral estrogens and estrogen implants. Both of these routes of delivery failed to provide stable plasma levels of estradiol and so, not surprisingly, were of no benefit to migraine. ${ }^{42}$ The fact that administration of a short-acting estrogen did not produce the same results as the long-acting supplements confirms the hypothesis that prolonged estrogen exposure is necessary for 'withdrawal' to trigger migraine.

More recent trials using more stable routes of delivery have shown efficacy (Table 1). De Lignières et al. studied 18 women with strictly defined menstrual migraine who completed a double-blind placebo-controlled crossover trial using $1.5 \mathrm{mg}$ estradiol gel, which allows a mean estradiol plasma level of $80 \mathrm{pg} / \mathrm{ml}$ to be reached, or placebo daily for 7 days during three consecutive cycles. ${ }^{44}$ Only eight menstrual attacks occurred during the 26 estrogentreated cycles compared with 26 attacks during the 27 placebo cycles. Furthermore, attacks during estrogen treatment were considerably milder and shorter than those during placebo.

Eighteen women also completed a similar trial by Dennerstein et al. for four cycles. ${ }^{45}$ The difference between estradiol gel and placebo was highly significant, favouring the estradiol gel, and less medication was used during active treatment. However, the results were not as impressive as the study by De Lignières et al. Dennerstein et al. comment that this might be because women in their study had menstrually related migraine rather than pure menstrual migraine and so migraine was only partially hormone dependent.

MacGregor et al. used $1.5 \mathrm{mg}$ estradiol gel in a doubleblind placebo-controlled study to prevent perimenstrual migraine attacks in 35 women with regular menstrual cycles and menstrual migraine or menstrually related migraine. ${ }^{46}$ Each woman was treated for up to six menstrual cycles (three cycles estradiol, three placebo). Women used the Clearblue ${ }^{\circledR}$ Fertility Monitor (Unipath Ltd, Bedford, UK) to identify ovulation, conducting a test each day as requested by the monitor, using a sample of early morning urine. Estradiol gel or placebo was first applied on the tenth day following the first day that the monitor signified ovulation and continued daily until, and including, the second day of menstruation. Estradiol was associated with a significant reduction in the duration and severity of migraine. As Somerville had found, there was a significant increase in the migraine immediately following cessation of active gel compared to placebo. Possible reasons for this post-gel estrogen 'withdrawal' migraine may be that the dose of estradiol was inadequate; the duration of treatment was too short; or perhaps that exogenous estrogen prevents the normal secretion of endogenous estrogen.

Lower doses of estrogen have not been as effective. ${ }^{47-49}$ Patches containing $25 \mu \mathrm{g}$ and $50 \mu \mathrm{g}$ estradiol achieve serum estradiol levels of $25 \mathrm{pg} / \mathrm{ml}$ and 40 $\mathrm{pg} / \mathrm{ml}$, respectively. In contrast, the $100 \mu \mathrm{g}$ patch effectively produces higher serum estradiol levels of 75 $\mathrm{pg} / \mathrm{ml}$, similar to levels attained with $1.5 \mathrm{mg}$ estradiol gel.

A study of women with migraine during the pill-free interval of combined oral contraceptives also suggested that $50 \mu \mathrm{g}$ patches are a suboptimal dose to prevent estrogen 'withdrawal' attacks associated with contraception. 50

\section{How do estrogens act in migraine?}

Migraine triggers are thought to activate specific centres in the brain stem in people with primed migrainous 'hyperexcitable' brains. 51 This in turn alters the levels of brain chemicals such as serotonin, which has been strongly implicated in migraine, disrupting the normal function of the hypothalamus. Activation of the trigeminovascular system and release of vasoactive neuropeptides results in vasodilation and transduction of central nociceptive information.

Estrogen and progesterone are neurosteroids, which influence the pain processing networks and vascular endothelium involved in the pathophysiology of migraine. Estrogen has potent effects on the serotonergic system, increasing serotonergic tone. It also facilitates the glutaminergic system, potentially enhancing neural excitability. In contrast, progesterone appears to activate GABAergic (gamma-aminobutyric acid) systems, suppressing neuronal reactivity, and modulates the effects of estrogen on the central nervous system. 52

Estrogens also raise levels of endorphins and aberrant opioid control of the hypothalamic-pituitary-adrenal axis has been reported in menstrual migraine. ${ }^{53,54}$ Fluctuating 


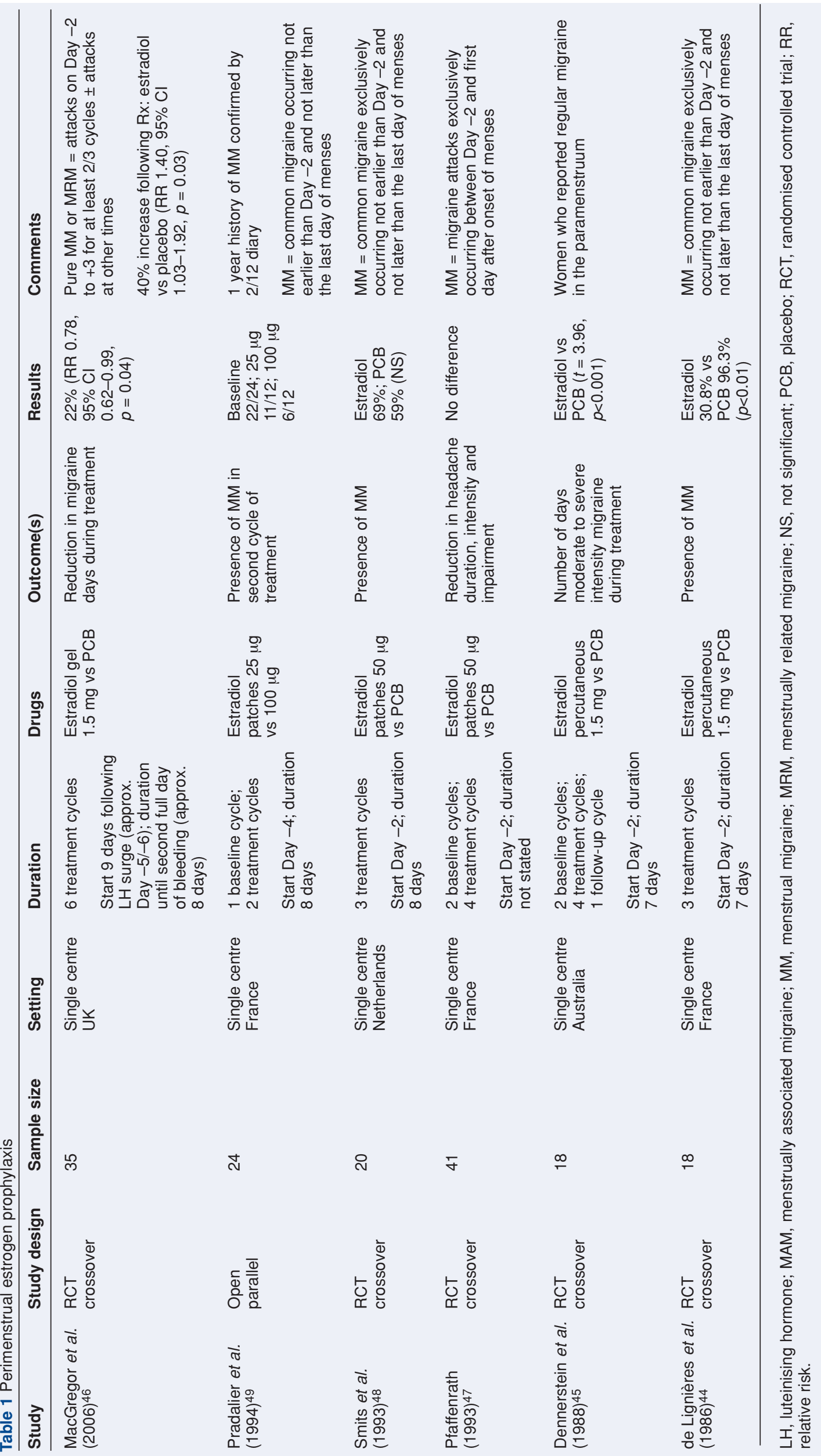




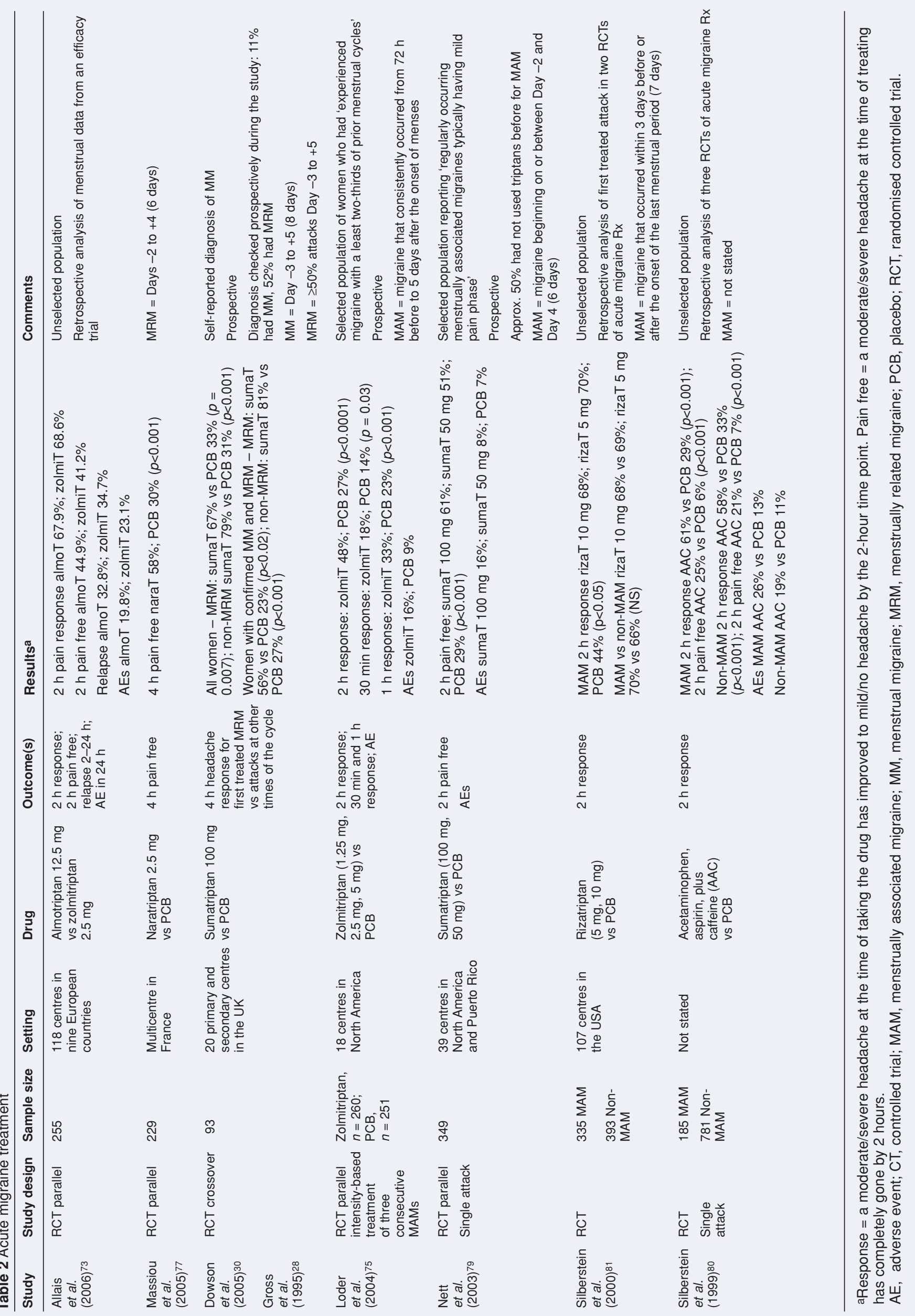




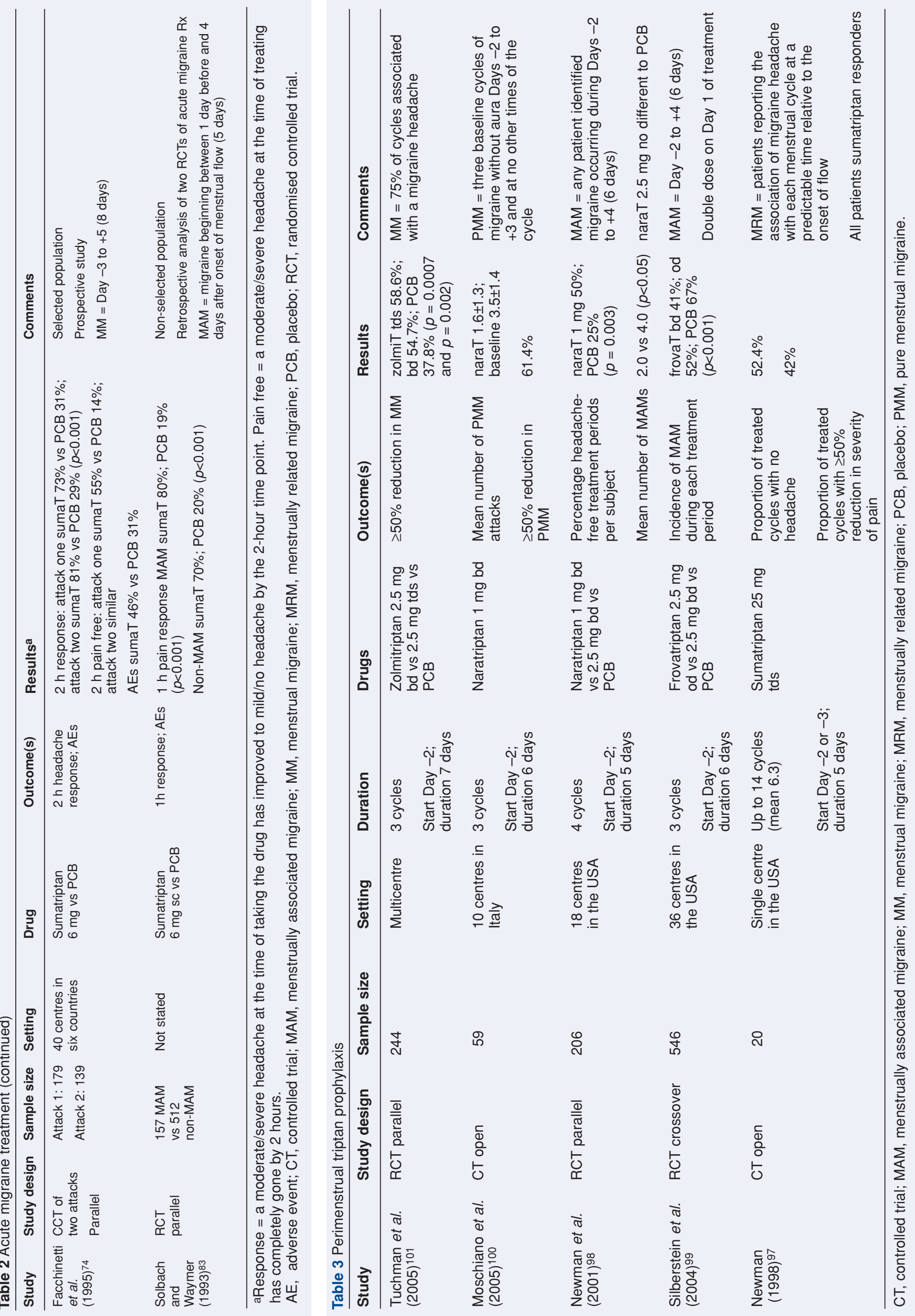




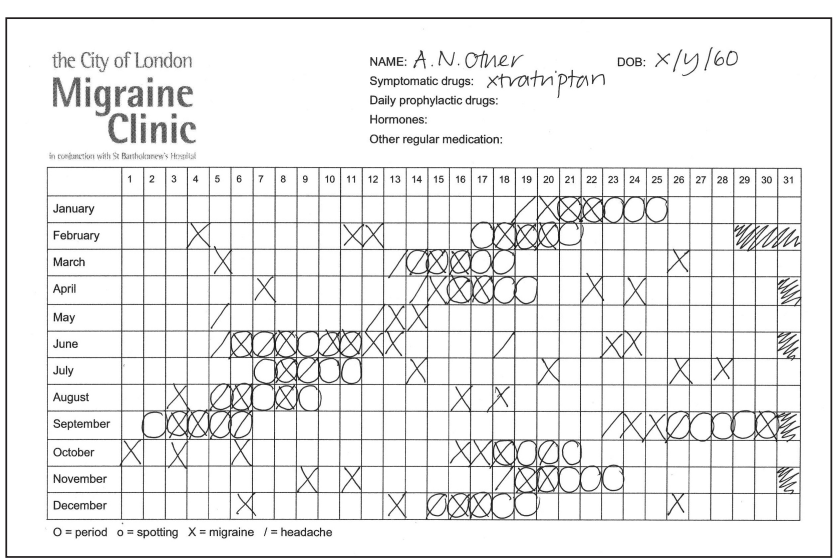

Figure 2 Diary card showing menstrually related migraine

estrogen levels are associated with impaired glucose tolerance in the luteal phase of the menstrual cycle. 55,56 This leads to reactive hypoglycaemia at the start of menstruation, which could trigger migraine. 57

That estrogens do not affect all women with migraine might be explained by the intrinsic estrogen receptor sensitivity of the hypothalamic neurons. Limited data imply that this may have a genetic basis. ${ }^{58}$ It has been suggested that when estrogen levels peak, increased neuronal excitability is balanced by homeostatic gene regulation in the brain cortex and nociceptive systems. As levels fall around menstruation, a mismatch in homeostatic gene regulation by estrogen unmasks non-nuclear mitogenactivated hyperexcitability of cell membranes, sensitising neurons to triggers that activate migraine attacks. At the trough of estrogen levels, the down-regulating effect on inflammatory genes is lost and peptide-modulated central sensitisation is increased, as is pain and disability of the migraine attack. 59

\section{Other mechanisms}

Other differences reported in menstrual migraine versus control groups include changes in aldosterone levels, ${ }^{60}$ intracellular magnesium ${ }^{61}$ and platelet homeostasis. ${ }^{62}$

Prostaglandins have also been implicated in menstrual migraine. ${ }^{63}$ In particular, entry of prostaglandins into the systemic circulation can trigger throbbing headache, nausea and vomiting. ${ }^{64}$ In the uterus prostaglandins are synthesised primarily by the endometrium. There is a threefold increase in prostaglandin levels in the uterine endometrium from the follicular to the luteal phase, with a further increase during menstruation. ${ }^{65}$ As a result of the 'withdrawal' of estrogen and progesterone the endometrium breaks down and prostaglandins are released. This causes vasoconstriction within the endometrium and disruption of endometrial cells, stimulating further prostaglandin synthesis. When an excessive amount of prostaglandins gain entrance to the circulation, other systemic symptoms occur that are characteristically associated with menorrhagia and/or dysmenorrhoea such as headache and nausea.66,67 Plasma taken during the premenstrual phase from women with dysmenorrhoea and re-infused post-menstruation into the same women resulted in premenstrual symptoms, including headache. ${ }^{68}$ Thus prostaglandins may have a specific role in migraine associated with dysmenorrhoea and/or menorrhagia. In support of this, prostaglandin inhibitors are effective for the prevention of menstrual attacks of migraine. 69

\section{Diagnosis}

Relying on the history to confirm the diagnosis can be misleading. ${ }^{9}$ Contemporaneous headache diaries recording menstrual periods and headache incidence should corroborate a history of migraine occurring around menstruation (Figure 2).$^{70}$ Headache occurring within -2 to +3 days of the onset of menstrual flow (counting the first day of bleeding as Day 1) in two out of three menstrual cycles is reasonable evidence of a clinically important link that might benefit from specific management strategies.

\section{Investigations}

Many women expect to have their migraine investigated, either with a hormone test or with a brain scan. Since no abnormalities of either have been identified in migraine or, more specifically, menstrual migraine there is no place for investigations other than those indicated to exclude suspected secondary headache resulting from underlying pathology.

\section{Interventions}

Once the diagnosis of migraine has been confirmed, a variety of management strategies are available, depending on individual symptoms and needs (Figure 3).

\section{Identification of non-hormonal triggers}

Assuming the concept of multiple factors acting in combination to trigger migraine, hormonal factors combine with non-hormonal triggers to increase the overall susceptibility to attacks at the time of menstruation. ${ }^{71}$ Therefore, every effort should be made to identify and eliminate non-hormonal triggers. In some cases, this may reduce the frequency and severity of all attacks. In others, non-hormonal attacks are eliminated while menstrual attacks persist.

\section{Acute}

The treatment of menstrual attacks of migraine is the same as for non-menstrual attacks. Acute treatment regimens usually include a combination of analgesics with or without prokinetic anti-emetics, NSAIDs, ergot derivatives and triptans (Table 2). ${ }^{72}$

Studies with almotriptan, eletriptan, frovatriptan, naratriptan, rizatriptan, sumatriptan and zolmitriptan suggest that they are effective for migraine attacks with menstruation. $28,30,73-83$

\section{Specific prophylaxis for menstrual migraine}

Only a small percentage of women will have menstrual migraine and wish to consider specific prophylaxis. Although many patients favour non-drug approaches, nondrug prophylaxis of menstrual migraine appears to be ineffective. ${ }^{84-86}$

None of the drugs and hormones recommended below are licensed for management of menstrual migraine because although effective in clinical trials, evidence is limited. Given that there are no investigations to identify the most effective prophylactic, an empirical approach is necessary, prescribing on a 'named' patient basis. Because of the fluctuating nature of migraine, it is sensible to try a method for at least three cycles before considering alternative prophylaxis.

\section{Non-steroidal anti-inflammatory drugs}

NSAIDs are effective prostaglandin inhibitors. They should be tried as first-line agents for migraine attacks that start on the first to third day of bleeding, particularly in the presence of dysmenorrhoea and/or menorrhagia. ${ }^{66,87}$ Side effects of NSAIDs include gastrointestinal disturbance. Misoprostol $800 \mu \mathrm{g}$ or omeprazole $20-40 \mathrm{mg}$ daily may give some gastroduodenal protection. ${ }^{88}$ Contraindications 
include peptic ulcer and aspirin-induced allergy. Interactions include anticoagulants and antihypertensive agents.

Mefenamic acid is an effective migraine prophylactic and has been reported to be particularly helpful in reducing migraine associated with menorrhagia and/or dysmenorrhoea. ${ }^{87,89} \mathrm{~A}$ dose of $500 \mathrm{mg}$, three to four times daily, may be started 2-3 days before the expected onset of menstruation, but is often effective even when started on the first day of bleeding; this is useful if periods are irregular. Treatment is usually only necessary for the first 2-3 days of bleeding.
Naproxen has also been found to be effective in the management of headache associated with dysmenorrhoea. Studies using $550 \mathrm{mg}$ once or twice daily perimenstrually have shown efficacy. ${ }^{90-92}$ Fenoprofen $600 \mathrm{mg}$ has been tried, taken twice daily from 3 days before the onset of menstruation until the last day of bleeding. ${ }^{93}$

Although an open-label study suggested that perimenstrual rofecoxib significantly reduced the frequency of perimenstrual migraine, there is no evidence that the new cyclo-oxygenase-2 (COX-2) inhibitors (rofecoxib, celecoxib, valdecoxib) are more effective than traditional NSAIDs. ${ }^{94}$ They are more

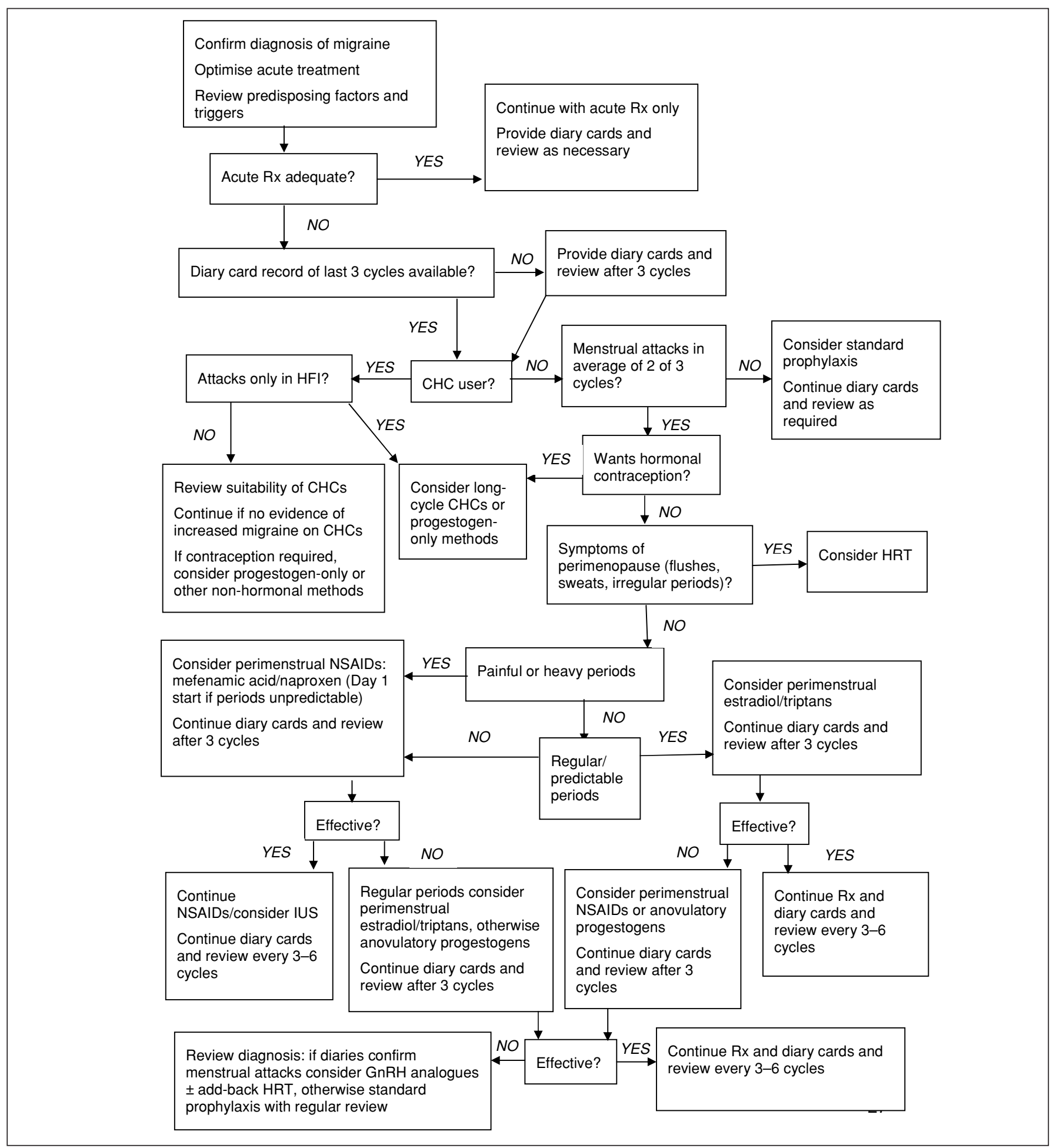

Figure 3 Algorithm for the management of menstrual attacks of migraine. $\mathrm{CHC}$, combined hormonal contraceptives; GnRH, gonadotrophinreleasing hormone; HFI, hormone-free interval; HRT, hormone replacement therapy; IUS, intrauterine system; NSAIDs, non-steroidal anti-inflammatory drugs 
costly but may provide a relative safety advantage for patients who need to use these agents for long periods of time and who are especially prone to gastrointestinal complications.

\section{Perimenstrual estrogen supplements}

Perimenstrual estrogen can be used only when menstruation is regular and predictable. If the woman has an intact uterus, no additional progestogens are necessary, provided that she is ovulating regularly. Ovulation can be confirmed using a home-use fertility monitor, which has the advantage of predicting menstruation. .55

Safety of estrogens is an important concern. Physiological doses of supplemental estrogens are well tolerated in clinical trials. ${ }^{46}$ Furthermore, there is no evidence of increased risk of thrombosis or cancer in women already producing endogenous estrogen. However, supplemental estrogens are not recommended for women who have estrogen-dependent tumours or other estrogendependent conditions, including a history of venous thromboembolism.

The recommended strategy for perimenstrual prophylaxis is estradiol gel $1.5 \mathrm{mg}$ applied daily from 2-3 days before expected menstruation for 7 days. ${ }^{96}$ Alternatively, transdermal estrogen $100 \mu \mathrm{g}$ can be used from 2-3 days before expected menstruation up to the fourth or fifth day of menstruation (i.e. two twice-weekly patches or one 7-day patch, although an additional patch may be necessary if menstruation is late). ${ }^{96}$

There is evidence that some women responding to estrogen supplements experience delayed attacks when the supplements are discontinued. ${ }^{41,46}$ Although there are no trial data, clinical practice suggests that for these women the duration of supplement use can be extended until Day 7 of the cycle, tapering the dose over the last 2 days.

\section{Perimenstrual triptans}

Trials using frovatriptan, naratriptan, sumatriptan and zolmitriptan for perimenstrual prophylaxis have suggested efficacy (Table 3). ${ }^{97-101}$

Triptan prophylaxis of menstrual migraine is costly and, to date, there are no trials that compare triptan prophylaxis of menstrual migraine with other lower-cost regimens. Furthermore, use of triptans for prophylaxis limits the choice for effective abortive therapy. Thus perimenstrual triptans should be considered for women with menstrual migraine in whom standard strategies fail.

\section{Continuous contraceptive strategies}

Continuous hormonal methods are particularly useful if cycles are irregular, or when the above strategies prove ineffective despite a convincing hormonal link.

\section{Continuous combined hormonal contraceptives}

Continuous hormones, in place of the usual regime of 3 weeks of active followed by 1 week of inactive pills or no therapy, has been recommended based on evidence that estrogen withdrawal provokes migraine in susceptible women. No double-blind, placebo-controlled trials, or even open-label trials, of this strategy in menstrual migraine have been performed. However, there is increasing clinical experience of their use in this way. ${ }^{102}$

Combined hormonal contraceptives should not be used by women with migraine with aura because of the synergistic increased risk of ischaemic stroke. ${ }^{103,104}$

\section{Progestogen-only methods}

Intramuscular depot medroxyprogesterone acetate (DepoProvera ${ }^{\circledR}$ ), subdermal etonorgestrel (Implanon ${ }^{\circledR}$ ) and oral desogestrel (Cerazette $\left.{ }^{\circledR}\right)$ inhibit ovulation. However, even when ovulation is suppressed irregular bleeding can occur, often associated with migraine. Somerville hypothesised that since fluctuations in estrogen levels can occur even when ovulation is suppressed, estrogen withdrawal will still act as a migraine trigger. ${ }^{105}$ Although irregular bleeding can occur in the early months of treatment, amenorrhoea is usual with continued use. It is therefore important to warn women who use this method that they should persevere until amenorrhoea is achieved.

The levonorgestrel intrauterine system (Mirena ${ }^{\circledR}$ ) is highly effective at reducing menstrual bleeding and associated pain. It can be considered for migraine related to menorrhagia. ${ }^{106}$ Systemic effects are usually minor but erratic bleeding and spotting is common in the early months of use. Most women are amenorrhoeic within 1 year. The treatment is not effective for women who are sensitive to estrogen withdrawal as a migraine trigger, as the majority of women still ovulate.

In general, standard contraceptive oral progestogens have little place in the management of menstrual migraine since most do not inhibit ovulation and are associated with a disrupted menstrual cycle. ${ }^{107}$ In contrast, unlicensed higher doses of oral progestogen, sufficient to inhibit ovulation, have shown benefit. 108

\section{Other therapies}

\section{Estradiol implants or patches}

These are the most effective method of obtaining high stable estrogen levels, inhibiting ovulation. Magos et al. showed that implant doses large enough to suppress ovulation and produce constant plasma estrogen levels achieved a $96 \%$ response rate in 24 patients studied. 109 However, in unhysterectomised women, progestogen opposition is necessary to protect the endometrium, which can mimic premenstrual symptoms, including headache. 110 Although there are no clinical trials for migraine, suppression of ovulation with $100 \mu \mathrm{g}$ patches used continuously together with continuous progestogen are likely to be effective with fewer progestogenic side effects. ${ }^{111}$

\section{Gonadotrophin-releasing hormone analogues}

Although effective, adverse effects of estrogen deficiency (e.g. hot flushes) restrict the use of gonadotrophinreleasing hormone $(\mathrm{GnRH})$ analogues. ${ }^{112}$ The hormones are also associated with a marked reduction in bone density and should not usually be used for longer than 6 months without regular monitoring and bone densitometry. 'Addback' continuous combined estrogen and progestogen can be given to counter these difficulties. ${ }^{113,114}$ Given these limitations, in addition to increased cost, such treatment should be instigated only in specialist departments.

\section{Magnesium}

Magnesium prolidone carboxylic acid $360 \mathrm{mg}$ decreased the duration and intensity of premenstrually occurring migraine in a placebo-controlled, double-blind study of 24 women with premenstrual syndrome and migraine. ${ }^{115}$ This study was principally aimed at identifying the effect of magnesium on a number of premenstrual problems, not just headache. The generalisability of the results to women whose menstrual headaches do not occur in association with other premenstrual symptoms is unclear. Diarrhoea is the major side effect and can sometimes be controlled by changing preparation. Magnesium oxide is widely available and the recommended dose is 300-600 mg daily. 


\section{Bromocriptine}

Bromocriptine, a dopamine agonist, inhibits $\mathrm{GnRH}$ and LH. Its use can result in reduced peak luteal estradiol levels and consequent reduced premenstrual estrogen withdrawal. Two studies have suggested the efficacy of bromocriptine in migraine, although larger double-blind placebocontrolled studies are necessary before it can be recommended. 116,117

\section{Anti-estrogens}

Danazol has been used with some effect but adverse effects restrict its use. ${ }^{118,119}$ Tamoxifen has been associated with varying effect on migraine. ${ }^{120-122}$

\section{Surgery}

Migraine is more likely to deteriorate after surgical menopause with bilateral oophorectomy. 54,123 If other medical problems require surgical menopause, the effects on migraine may be lessened with estrogen replacement therapy, as for natural and medical menopause. ${ }^{109,114}$

\section{What to do when nothing works}

In most cases, menstrual migraine can be effectively controlled by following the strategies detailed in the preceding paragraphs. However, a few cases may be refractory, even to total suppression of the menstrual cycle. The usual reason for such treatment failure is incorrect diagnosis. Therefore, if migraine remains refractory despite trials of several different strategies given in an adequate dose for an adequate duration, reconsider the diagnosis.

A common cause for refractory migraine is medication overuse. $^{2}$ All symptomatic drugs including analgesics, triptans and ergots are effective provided that they are used intermittently and not regularly more often than 2 or 3 days a week. More frequent use can perpetuate headache rather than relieve it. ${ }^{124}$

The exact mechanism of medication overuse headache is unknown but it is generally believed to involve a disturbance of central pain systems. Frequency of dosing is important: low daily dosing carries a greater risk than larger intermittent dosing. The only effective treatment is to stop the drugs, either immediately or by gradually reducing the amount over several weeks. Up to $60 \%$ of sufferers who are withdrawn from drugs improve, although it can take up to 3 months before full improvement is seen and the relapse rate is high. ${ }^{124}$

\section{Conclusions}

Despite the high prevalence of menstrual attacks of migraine, limited recognition of this condition has resulted in unnecessary disability. Use of simple diary cards to establish the association between migraine and menstruation can enable the instigation of more effective treatment strategies and improve the quality of the lives of migraineurs and those around them.

Statements on funding and competing interests

Funding The author received funding from Unipath to attend the 2003 FIGO Conference and has been sponsored to attend Faculty meetings by Organon.

Competing interests The author has attended advisory board meetings for Organon and Vernalis.

\section{References}

1 Higgins J, Green S (eds). Cochrane Handbook for Systematic Reviews of Interventions 4.2.6 (updated September 2006). Chichester, UK: John Wiley \& Sons, Ltd, 2006.

2 Headache Classification Subcommittee of the Internationa Headache Society (IHS). The International Classification of Headache Disorders (2nd edn). Cephalalgia 2004; 24(Suppl. 1): $1-160$.
3 Bille B. Migraine in school children. Acta Paediatr Scand 1962; 51(Suppl. 136): 1-151.

4 Stewart W, Linet M, Celentano D, Van Natta M, Ziegler D. Ageand sex-specific incidence rates of migraine with and without visual aura. Am J Epidemiol 1991; 134: 1111-1120.

5 Stewart WF, Lipton RB, Celentano DD, Reed ML. Prevalence of migraine headache in the United States. Relation to age, income, race, and other sociodemographic factors. JAMA 1992; 267: 64-69.

6 Rasmussen BK, Jensen R, Schroll M, Olesen J. Epidemiology of headache in a general population - a prevalence study. $J$ Clin Epidemiol 1991; 44: 1147-1157.

7 O'Brien B, Goeree R, Streiner D. Prevalence of migraine headache in Canada: a population-based survey. Int $J$ Epidemiol 1994; 23: 1020-1026.

8 Launer L, Terwindt G, Ferrari M. The prevalence and characteristics of migraine in a population-based cohort, The GEM study. Neurology 1999; 53: 537-542.

9 MacGregor EA, Igarashi H, Wilkinson M. Headaches and hormones: subjective versus objective assessment. Headache Quarterly 1997; 8: 126-136.

10 Couturier EG, Bomhof MA, Neven AK, van Duijn NP. Menstrual migraine in a representative Dutch population sample: prevalence, disability and treatment. Cephalalgia 2003; 23: 302-308.

11 Dzoljic E, Sipetic S, Vlajinac H, Marinkovic J, Brzakovic $\mathrm{B}$, Pokrajac $\mathrm{M}$, et al. Prevalence of menstrually related migraine and nonmigraine primary headache in female students of Belgrade University. Headache 2002; 42: 185-193.

12 Granella F, Sances G, Zanferrari C, Costa A, Martignoni E, Manzoni GC. Migraine without aura and reproductive life events: a clinical epidemiological study in 1300 women. Headache 1993; 33: 385-389.

13 MacGregor EA, Chia H, Vohrah RC, Wilkinson M. Migraine and menstruation: a pilot study. Cephalalgia 1990; 10: 305-310.

14 MacGregor EA, Brandes J, Eikermann A, Giammarco R. Impact of migraine on patients and their families: the Migraine And Zolmitriptan Evaluation (MAZE) survey - Phase III. Curr Med Res Opin 2004; 20: 1143-1150.

15 Bille B. A 40-year follow-up of school children with migraine. Cephalalgia 1997; 17: 488-491.

16 Steiner TJ, Scher Al, Stewart WF, Kolodner K, Liberman J, Lipton RB. The prevalence and disability burden of adult migraine in England and their relationships to age, gender and ethnicity. Cephalalgia 2003; 23: 519-527.

17 Russell MB, Rasmussen BK, Fenger K, Olesen J. Migraine without aura and migraine with aura are distinct clinical entities: a study of four hundred and eighty-four male and female migraineurs from the general population. Cephalalgia 1996; 16: 239-245.

18 MacGregor EA, Hackshaw A. Prevalence of migraine on each day of the natural menstrual cycle. Neurology 2004; 63: 351-353.

19 MacGregor EA, Frith A, Ellis J, Aspinall L, Hackshaw A. Incidence of migraine relative to menstrual cycle phases of rising and falling estrogen. Neurology 2006; 13 September (Epub ahead of print).

20 Waters W, O'Connor P. Epidemiology of headache and migraine in women. J Neurol Neurosurg Psychiatry 1971; 34: 148-153.

21 Dalton K. Progesterone suppositories and pessaries in the treatment of menstrual migraine. Headache 1973; 13: 151-159.

22 Johannes CB, Linet MS, Stewart WF, Celentano DD, Lipton RB, Szklo M. Relationship of headache to phase of the menstrual cycle among young women: a daily diary study. Neurology 1995; 45: 1076-1082.

23 Stewart WF, Lipton RB, Chee E, Sawyer J, Silberstein SD. Menstrual cycle and headache in a population sample of migraineurs. Neurology 2000; 55: 1517-1523.

24 Bousser M, Massiou H. Migraine in the reproductive cycle. In: Olesen J, Tfelt-Hansen P, Welch K (eds), The Headaches. New York, NY: Raven Press, 1993; 413-419.

25 Cupini L, Matteis M, Troisi E, Calabresi P, Bernardi G, Silvestrini M. Sex-hormone-related events in migrainous females. A clinical comparative study between migraine with aura and migraine without aura. Cephalalgia 1995; 15: 140-144.

26 Rasmussen BK, Olesen J. Migraine with aura and migraine 
without aura: an epidemiological study. Cephalalgia 1992; 12: 221-228; discussion 186.

27 Granella F, Sances G, Pucci E, Nappi RE, Ghiotto N, Napp G. Migraine with aura and reproductive life events: a case control study. Cephalalgia 2000; 20: 701-707.

28 Gross M, Barrie M, Bates D, Dowson A, Elrington G. The efficacy of sumatriptan in menstrual migraine. Eur $J$ Neurol 1995; 2: 144-145.

29 Visser WH, Jaspers NMW, de Vriend RHM, Ferrari MD. Risk factors for headache recurrence after sumatriptan: a study in 366 migraine patients. Cephalalgia 1996; 16: 264-269.

30 Dowson AJ, Massiou H, Aurora SK. Managing migraine headaches experienced by patients who self-report with menstrually related migraine: a prospective, placebocontrolled study with oral sumatriptan. J Headache Pain 2005; 6: 81-87.

31 Martin VT, Wernke S, Mandell K, Ramadan N, Kao L, Bean J, et al. Defining the relationship between ovarian hormones and migraine headache. Headache 2005; 45: 1190-1201.

32 Granella F, Sances G, Allais G, Nappi RE, Tirelli A, Benedetto $\mathrm{C}$, et al. Characteristics of menstrual and nonmenstrual attacks in women with menstrually related migraine referred to headache centres. Cephalalgia 2004; 24: 707-716.

33 World Health Organization (WHO). Mental Health: New Understanding, New Hope. Geneva, Switzerland: WHO, 2001.

34 Lipton RB, Bigal ME, Kolodner K, Stewart WF, Liberman JN, Steiner TJ. The family impact of migraine: population-based studies in the USA and UK. Cephalalgia 2003; 23: 429-440.

35 Dowson AJ, Kilminster SG, Salt R, Clark M, Bundy MJ. Disability associated with headaches occurring inside and outside the menstrual period in those with migraine: a general practice study. Headache 2005; 45: 274-282.

36 Whitty CW, Hockaday JM, Whitty MM. The effect of oral contraceptives on migraine. Lancet 1966; i(7442): 856-859.

37 Kudrow $\mathrm{L}$. The relationship of headache frequency to hormone use in migraine. Headache 1975; 15: 36-40.

38 Dennerstein L, Laby B, Burrows GD, Hyman GJ. Headache and sex hormone therapy. Headache 1978; 18: 146-153.

39 Lichten EM, Lichten JB, Whitty A, Pieper D. The confirmation of a biochemical marker for women's hormonal migraine: the depo-estradiol challenge test. Headache 1996; 36: 367-371.

40 Somerville BW. The role of estradiol withdrawal in the etiology of menstrual migraine. Neurology 1972; 22: 355-365.

41 Somerville BW. Estrogen-withdrawal migraine. I. Duration of exposure required and attempted prophylaxis by premenstrual estrogen administration. Neurology 1975; 25: 239-244.

42 Somerville BW. Estrogen-withdrawal migraine II. Attempted prophylaxis by continuous estradiol administration. Neurology 1975; 25: 245-250.

43 Epstein MT, Hockaday JM, Hockaday TD. Migraine and reporoductive hormones throughout the menstrual cycle. Lancet 1975; 1(7906): 543-548.

44 de Lignières $B$, Vincens M, Mauvais-Jarvis P, Mas JL, Touboul PJ, Bousser MG. Prevention of menstrual migraine by percutaneous oestradiol. Br Med J (Clin Res Ed) 1986; 293(6561): 1540

45 Dennerstein L, Morse C, Burrows G, Oats J, Brown J, Smith M. Menstrual migraine: a double-blind trial of percutaneous estradiol. Gynecol Endocrinol 1988; 2: 113-120.

46 MacGregor EA, Frith A, Ellis J, Aspinall L, Hackshaw A Prevention of menstrual attacks of migraine: a double-blind placebo-controlled crossover study. Neurology 2006; (in press).

47 Pfaffenrath V. Efficacy and safety of percutaneous estradiol vs. placebo in menstrual migraine. Cephalalgia 1993; 13(Suppl. 13): 244.

48 Smits MG, van der Meer YG, Pfeil JP, Rijnierse JJ, Vos AJ. Perimenstrual migraine: effect of Estraderm TTS and the value of contingent negative variation and exteroceptive temporalis muscle suppression test. Headache 1994; 34: 103-106.

49 Pradalier A, Vincent D, Beaulieu P, Baudesson G, Launey J-M. Correlation between estradiol plasma level and therapeutic effect on menstrual migraine. In: Rose F (ed.), New Advances in Headache Research. London, UK: Smith-Gordon, 1994: 129-132.

50 MacGregor EA, Hackshaw A. Prevention of migraine in the pillfree interval of combined oral contraceptives: a double-blind, placebo-controlled pilot study using natural oestrogen supplements. J Fam Plann Reprod Health Care 2002; 28: 27-31.

51 Lang E, Kaltenhauser M, Neundorfer B, Seidler S.
Hyperexcitability of the primary somatosensory cortex in migraine - a magnetoencephalographic study. Brain 2004; 127(Pt 11): 2459-2469.

52 Martin VT, Behbehani M. Ovarian hormones and migraine headache: understanding mechanisms and pathogenesis Part I. Headache 2006; 46: 3-23.

53 Facchinetti F, Martignoni E, Fioroni L, Sances G, Genazzani AR. Opioid control of the hypothalamus-pituitary-adrenal axis cyclically fails in menstrual migraine. Cephalalgia 1990; 10: 51-56.

54 Neri I, Granella F, Nappi R, Manzoni G, Facchinetti F, Genazzani A. Characteristics of headache at menopause: a clinico-epidemiologic study. Maturitas 1993; 17: 31-37.

55 Bertoli A, De Pirro R, Fusco A, Greco A, Magnatta R, Lauro R. Differences in insulin receptors between men and menstruating women and influence of sex hormones on insulin binding during the menstrual cycle. J Clin Endocrinol Metab 1980; 50: 246-250.

56 Jarrett R, Graver $\mathrm{H}$. Changes in oral glucose tolerance during the menstrual cycle. BMJ 1968; 2: 528-529.

57 Okey R, Robb E. Studies of the metabolism of women. 1. Variations in the fasting blood sugar level and in sugar tolerance in relation to the menstrual cycle. J Biol Chem 1925; 65: 165-186.

58 Berman NE, Puri V, Chandrala S, Puri S, Macgregor R, Liverman CS, et al. Serotonin in trigeminal ganglia of female rodents: relevance to menstrual migraine. Headache 2006; 46: 1230-1245.

59 Welch KM, Brandes JL, Berman NE. Mismatch in how oestrogen modulates molecular and neuronal function may explain menstrual migraine. Neurol Sci 2006; 27(Suppl. 2): S190-S192.

60 Nattero G. Menstrual headache. Adv Neurol 1982; 33: 215-226.

61 Facchinetti F, Sances G, Borella P, Genazzani AR, Nappi G. Magnesium prophylaxis of menstrual migraine: effects on intracellular magnesium. Headache 1991; 31: 298-301.

62 Allais G, Facco G, Ciochetto D, De LC, Fiore M, Benedetto C. Patterns of platelet aggregation in menstrual migraine. Cephalalgia 1997; 17(Suppl. 20): 39-41.

63 Horrobin D. Prostaglandins and migraine. Headache 1977; 16: 113-116.

64 Carlson L, Ekelund L-G, Orö L. Clinical and metabolic effects of different doses of prostaglandin E1 in man. Acta Med Scand 1968; 183: 423-430.

65 Downie J, Poyser N, Wonderlich M. Levels of prostaglandins in human endometrium during normal menstrual cycle. J Physiol 1974; 236: 465-472.

66 Chan W. Prostaglandins and nonsteroidal antiinflammatory drugs in dysmenorrhoea. Ann Rev Pharmacol Toxicol 1983; 23: $131-149$.

67 Benedetto C. Eicosanoids in primary dysmenorrhea, endometriosis and menstrual migraine. Gynecol Endocrinol 1989; 3: 71-94

68 Irwin J, Morse E, Riddick D. Dysmenorrhoea induced by autologous transfusion. Obstet Gynecol 1981; 58: 286-290.

69 Pradalier A, Clapin A, Dry J. Treatment review: non-steroidal anti-inflammatory drugs in the treatment and long-term prevention of migraine attacks. Headache 1988; 28: 550-557.

70 Loder E. Migraine and menstruation. J Soc Obstet Gynaecol Can 2000; 22: 512-517.

71 Amery WK, Vandenbergh V. What can precipitating factors teach us about the pathogenesis of migraine? Headache 1987; 27: $146-150$

72 Steiner TJ, MacGregor EA, Davies PTG. Guidelines for All Doctors in the Diagnosis and Management of Migraine and Tension-type Headache (2nd edn). 2004. http://64.227. 208.149/NS_BASH/BASH_guideline31Aug05.pdf [Accessed 8 November 2006].

73 Allais G, Acuto G, Cabarrocas X, Esbri R, Benedetto C, Bussone G. Efficacy and tolerability of almotriptan versus zolmitriptan for the acute treatment of menstrual migraine. Neurol Sci 2006; 27(Suppl. 2): S193-S197.

74 Facchinetti F, Bonellie G, Kangasniemi P, Pascual J, Shuaib A. The efficacy and safety of subcutaneous sumatriptan in the acute treatment of menstrual migraine. The Sumatriptan Menstrual Migraine Study Group. Obstet Gynecol 1995; 86: 911-916.

75 Loder E, Silberstein SD, Abu-Shakra S, Mueller L, Smith T. Efficacy and tolerability of oral zolmitriptan in menstrually associated migraine: a randomized, prospective, parallel- 
group, double-blind, placebo-controlled study. Headache 2004; 44: 120-130.

76 MacGregor EA, Keywood C. Frovatriptan is effective in menstrually associated migraine. Cephalalgia 2000; 20: 345.

77 Massiou H, Jamin C, Hinzelin G, Bidaut-Mazel C. Efficacy of oral naratriptan in the treatment of menstrually related migraine. Eur J Neurol 2005; 12: 774-781.

78 Massiou H, Pitei D, Poole P, Sikes C. Efficacy of eletriptan for the treatment of migraine in women with menstrually associated migraine, and in women on contraceptives or hormone replacement therapy: meta-analyses of randomized clinical trials. Cephalalgia 2000; 20: 435.

79 Nett R, Landy S, Shackelford S, Richardson MS, Ames M, Lener M. Pain-free efficacy after treatment with sumatriptan in the mild pain phase of menstrually associated migraine. Obstet Gynecol 2003; 102: 835-842.

80 Silberstein S, Armellino J, Hoffman H, Battikha JP, Hamelsky SW, Stewart WF, et al. Treatment of menstruation-associated migraine headache with the nonprescription combination of acetaminophen, aspirin, and caffeine: results from three randomized, placebo-controlled studies. Clin Ther 1999; 21 . 475-491.

81 Silberstein SD, Massiou H, Le Jeunne C, Johnson-Pratt L, McCarroll KA, Lines CR. Rizatriptan in the treatment of menstrual migraine. Obstet Gynecol 2000; 96: 237-242.

82 Silberstein SD, Massiou H, McCarroll KA, Lines CR. Further evaluation of rizatriptan in menstrual migraine: retrospective analysis of long-term data. Headache 2002; 42: 917-923.

83 Solbach MP, Waymer RS. Treatment of menstruationassociated migraine headache with subcutaneous sumatriptan. Obstet Gynecol 1993; 82: 769-772.

84 Solbach P, Sargent J, Coyne L. Menstrual migraine headache: results of a controlled, experimental, outcome study of nondrug treatments. Headache 1984; 24: 75-78.

85 Szekely B, Botwin D, Eidelman B, Becker M, Elman N Schemm R. Nonpharmacological treatment of menstrual headache: relaxation-biofeedback behaviour therapy and person-centred insight therapy. Headache 1986; 26: 86-92.

86 Linde M, Fiell A, Carlsson J, Dahlof C. Role of the needling per se in acupuncture as prophylaxis for menstrually related migraine: a randomized placebo-controlled study. Cephalalgia 2005; 25: 41-47.

87 Johnson R, Hornabrook R, Lambie D. Comparison of mefenamic acid and propranolol with placebo in migraine prophylaxis. Acta Neurol Scand 1986; 73: 490-492.

88 Gøtzsche P. Non-steroidal anti-inflammatory drugs. BMJ 2000; 320: 1058-1061.

89 Owens P. Prostaglandin synthetase inhibitors in the treatment of primary dysmenorrhoea: outcome trials reviewed. $A m \mathrm{~J}$ Obstet Gynecol 1984; 148: 96

90 Sargent J, Solbach P, Damasio H, Baumel B, Corbett J, Eisner $\mathrm{L}$, et al. A comparison of naproxen sodium to propranolol hydrochloride and a placebo control for the prophylaxis of migraine headache. Headache 1985; 25: 320-324.

91 Szekely B, Meeryman S, Post G. Prophylactic effects of naproxen sodium on perimenstrual headache: a double-blind, placebo-controlled study. Cephalalgia 1989; 9: 452-453.

92 Nattero G, Allais G, De Lorenzo C, Ferrando M, Ferrari P, Benedetto $\mathrm{C}$, et al. Biological and clinical effects of naproxen sodium in patients with menstrual migraine. Cephalalgia 1991; 11(Suppl. 11): 201-202.

93 Diamond S. Menstrual migraine and non-steroidal antiinflammatory agents. Headache 1984; 24: 52.

94 Von Seggern RL, Mannix LK, Adelman JU. Rofecoxib in the prevention of perimenstrual migraine: an open-label pilot trial. Headache 2004; 44: 160-165.

95 MacGregor EA, Frith A, Ellis J, Aspinall L. Predicting menstrual migraine with a home-use fertility monitor. Neurology 2005; 64: $561-563$

96 MacGregor EA. Migraine in Women (3rd edn). London, UK: Martin Dunitz, 2003.

97 Newman LC, Lipton RB, Lay CL, Solomon S. A pilot study of oral sumatriptan as intermittent prophylaxis of menstruationrelated migraine. Neurology 1998; 51: 307-309.

98 Newman L, Mannix LK, Landy S, Silberstein S, Lipton RB, Putnam DG, et al. Naratriptan as short-term prophylaxis of menstrually associated migraine: a randomized, double-blind, placebo-controlled study. Headache 2001; 41: 248-256.

99 Silberstein SD, Elkind AH, Schreiber C, Keywood C. A randomized trial of frovatriptan for the intermittent prevention of menstrual migraine. Neurology 2004; 63: 261-269.
100 Moschiano F, Allais G, Grazzi L, Usai S, Benedetto C, D'Amico $\mathrm{D}$, et al. Naratriptan in the short-term prophylaxis of pure menstrual migraine. Neurol Sci 2005; 26(Suppl. 2): s162-s166.

101 Tuchman M, Hee A, Emeribe U. Oral zolmitriptan $2.5 \mathrm{mg}$ demonstrates high efficacy and good tolerability in the prophylactic treatment of menstrual migraine headaches. Headache 2005; 45: 771-772.

102 Edelman A, Gallo MF, Nichols MD, Jensen JT, Schulz KF, Grimes DA. Continuous versus cyclic use of combined oral contraceptives for contraception: systematic Cochrane review of randomized controlled trials. Hum Reprod 2006; 21: 573-578.

103 World Health Organization (WHO). Medical Eligibility Criteria for Contraceptive Use (3rd edn). Geneva, Switzerland: WHO, 2004

104 MacGregor EA, Guillebaud J. Combined oral contraceptives, migraine and ischaemic stroke. Clinical and Scientific Committee of the Faculty of Family Planning and Reproductive Health Care and the Family Planning Association. Br J Fam Plann 1998; 24: 55-60.

105 Somerville B, Carey M. The use of continuous progestogen contraception in the treatment of migraine. Med J Aust 1970; 1 : 1043-1045.

106 Crosignani P, Vercellini P, Mosconi P, Oldani S, Cortesi I, De Giorgi $\mathrm{O}$. Levonorgestrel-releasing intrauterine device versus hysteroscopic endometrial resection in the treatment of dysfunctional uterine bleeding. Obstet Gynecol 1997; 90: 257-263.

107 Chumnijaraki T, Sunyavivat S, Onthuam Y, Udomprasetgurl V. Study on the factors associated with contraception discontinuation in Bangkok. Contraception 1984; 29: 241-248.

108 Davies P, Fursdon-Davies C, Rees M. Progestogens for menstrual migraine. J Br Menopause Soc 2003; 9: 134

109 Magos AL, Zilkha KJ, Studd JW. Treatment of menstrual migraine by oestradiol implants. I Neurol Neurosurg Psychiatry 1983; 46: 1044-1046.

110 Magos A, Brewster E, Singh R, O'Dowd T, Brincat M, Studd JW. The effects of norethisterone in postmenopausal women on oestrogen replacement therapy: a model for the premenstrual syndrome. Br J Obstet Gynaecol 1986; 93: 1290-1296.

111 Domoney C, Panay N, Hawkins A, Studd J. The treatment of premenstrual syndrome (PMS) with transdermal oestrogen. Presentation at the XVII FIGO World Congress of Gynecology and Obstetrics, 2-7 November 2003, Santiago, Chile.

112 Holdaway IM, Parr CE, France J. Treatment of a patient with severe menstrual migraine using the depot LHRH analogue Zoladex. Aust N Z J Obstet Gynaecol 1991; 31: 164-165.

113 Murray SC, Muse KN. Effective treatment of severe menstrual migraine headaches with gonadotropin-releasing hormone agonist and 'add-back' therapy. Fertil Steril 1997; 67: 390-393.

114 Martin V, Wernke S, Mandell K, Zoma W, Bean J, Pinney S, et al. Medical oophorectomy with and without estrogen add-back therapy in the prevention of migraine headache. Headache 2003; 43: 309-321.

115 Facchinetti F, Montorsi S, Borella P, Sances G, Neri I, Martignoni $\mathrm{E}$, et al. Magnesium prevention of premenstrual migraine: a placebo controlled study. In: Rose FC (ed.), New Advances in Headache Research. London, UK: Smith-Gordon, 1991; 329-332.

116 Hockaday JM, Peet KM, Hockaday TD. Bromocriptine in migraine. Headache 1976; 16: 109-114.

117 Herzog AG. Continuous bromocriptine therapy in menstrual migraine. Neurology 1997; 48: 101-102.

118 Calton G, Burnett J. Danazol and migraine. N Engl J Med 1984: 310: 721-722.

119 Lichten EM, Bennett RS, Whitty AJ, Daoud Y. Efficacy of danazol in the control of hormonal migraine. $J$ Reprod Med 1991; 36: 419-424.

120 Powles T. Prevention of migrainous headaches by tamoxifen [Letter]. Lancet 1986; 2: 1344.

121 O'Dea JP, Davis EH. Tamoxifen in the treatment of menstrual migraine. Neurology 1990; 40: 1470-1471.

122 Mathew P, Fung F. Recapitulation of menstrual migraine with tamoxifen. Lancet 1999; 353(9151): 467-468.

123 Dalton K. Discussion on the aftermath of hysterectomy and oophorectomy. Proc R Soc Med 1956; 50: 415-418.

124 Diener HC, Limmroth V. Medication-overuse headache: a worldwide problem. Lancet Neurol 2004: 3: 475-483. 